\title{
CADOProSys Software. General structure
}

\author{
Catrina Chivu, ${ }^{1,}$, Cătălin-Iulian Chivu ${ }^{1}$, and Magdalena Barbu ${ }^{1}$ \\ ${ }^{1}$ Engineering and Industrial Management Department, Transilvania University of Brasov, 500174 \\ MihaiViteazu, Brasov, Romania
}

\begin{abstract}
Design of flexible manufacturing systems is a challenge based on the field, structure, medium and long term management strategies of the production system. On the market there are many ERP software designed for integrated management. Generally, this type of software is not focused on manufacturing lines, managing only the documents inside the manufacturing systems, being not appropriate for design. Anyway, all the applications from the market assumed that the user knows how to design PLM software. This assumption was the motivation for the authors of the present paper to design a computer aided application that will help the beginners, the graduates, to design a manufacturing line. The software includes many modules. Thus, there are modules for designing: space, number of machine-tools and/ or equipment, human resource, layout, production planning, logistics (supply-chain and material handling), automation. The software was designed especially for automotive industry, industry that dominates the Brasov area. Present paper is focused on the general structure of the CADOProSys (Computer Aided Design and Optimisation of Production Systems) Software, including the logic diagram and some opportunities provided by the application.
\end{abstract}

\section{Introduction}

\subsection{Market solutions}

For any company, to be competitive via market implies to make difficult decisions, to be as much as it can, innovative. Obviously, innovation requires investment (time and capital): it is risky, and return on investment can span several years. Thus, the majority of products introduced into the market are only marginally different from their competitors and rarely survive beyond an initial period.

In a business plan, designing and planning the new production system is one of the most important parts of the start-up. Is a challenge process and requires experience and sometimes intuition because is all about productivity, quality, e-business, local $/ \&$ global competition and customer service, or in other words is about operations management.

Any business organizations, but especially an automotive one, have three basic functional areas: finance, marketing and operations (figure 1). "Finance" is responsible for securing financial resources, allocating those resources, budgeting, analysing investment

${ }^{*}$ Corresponding author: catrina.c@unitbv.ro 
proposals, and providing funds for operations. "Marketing" is responsible for assessing consumer wants and needs, selling and promoting the organization's goods. "Operations" is responsible for producing the goods [1].

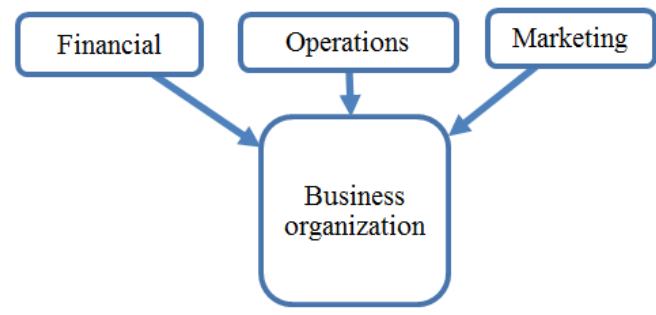

Fig. 1. Functional areas of a business organization.

Based on these areas, on the market, there is a lot of ERP (Enterprise Resource Planning) software, focused on company's management. Thus, these systems gather, under the umbrella of a single IT platform, human resources, know-how, software and hardware. So whether we are talking about sales, purchasing, production, finance or accounting department, all these departments within a firm can be integrated into a single system.

According to a specialised website [2], first ten most used software, in the field of manufacturing, are listed in Table 1.

Table 1. Software used for management in the field of manufacturing [2].

\begin{tabular}{|l|l|l|l|l|}
\hline No. & Software & Firm type $^{\mathbf{1}}$ & Platform & Price $^{2}$ \\
\hline 1. & E2 Shop System Software & S, M & Windows & $*$ \\
\hline 2. & MIE Trak PRO & S, M & Mac OS, Windows, Linux & $*$ \\
\hline 3. & Global Shop Solutions & S, M & Mac OS, Windows, Linux & $* *$ \\
\hline 4. & EnterpriseIQ & S, M & Mac OS, Windows, Linux & $* *$ \\
\hline 5. & QT9 Quality Management & S, M, L & Mac OS, Windows, Linux & $*$ \\
\hline 6. & SAP Business One & S, M, L & Mac OS, Windows, Linux & $* * *$ \\
\hline 7. & Oracle JD Edwards - Manufacturing & S, M, L & Mac OS, Windows, Linux & $* * * *$ \\
\hline 8. & Synergy SPC & S, M, L & Mac OS, Windows, Linux & $*$ \\
\hline 9. & OmegaCube ERP & A & Mac OS, Windows, Linux & $*$ \\
\hline 10. & Infor VISUAL ERP & S, M & Mac OS, Windows, Linux & $* * *$ \\
\hline
\end{tabular}

${ }^{1} \mathrm{~S}=$ small; $\mathrm{M}=$ medium; $\mathrm{L}=$ large

$2 *=$ low, $5^{*}=$ very expensive

All these package offer management for both discrete and repetitive manufactures in the automotive. There are managed accounting, business analytics human resources, inventory control, invoicing, quality control \& inspection, supply chain, repair \& maintenance, etc. Each of this software may be used for complete enterprise resource planning and manufacturing execution functionality including generating shipping labels and packing slips and then tracks shipments online to multiple shipping addresses.

All these software are focused in managing existing manufacturing systems, with fewer instruments for designing new systems. From digital manufacturing solutions point of view, there is very few number of software, most of the being "object" oriented. Thus, there is software for assembly process simulation (e.g. DELMIA) [3]. One of the most powerful and complex instrument is offered by Siemens, through Tecnomatix software [4]. This software allows designing innovative systems based on product engineering, manufacturing engineering and production. It is a very complex instrument that may be used to increase productivity through planning and to manage manufacturing by optimising subsystems. The most disadvantageous aspect of this product is the complexity, which make it usable only 
by specialists, not beginners in the field of manufacturing system design. Thus, if we are talking about undergraduates, they do not have all information and knowledge to be able to accurately and realistically design a manufacturing system with Tecnomatics because they do not control the technical parameters involved in design. This is the main reason that led to the development of software, enabling the undergraduates to design a manufacturing system.

\subsection{Product design concept}

Product development or product design, regardless of the type of product, even software, implies a set of activities beginning with the market opportunity and ending in the production, sale and delivery of the product.

There is no ideal recipe to design software. Basically, almost half of the methods are focused on how the template of a program is derived from the description of the input data [5-9]. The methods used in developing software may be grouped as shown in Figure 2 (as difficulty increases).

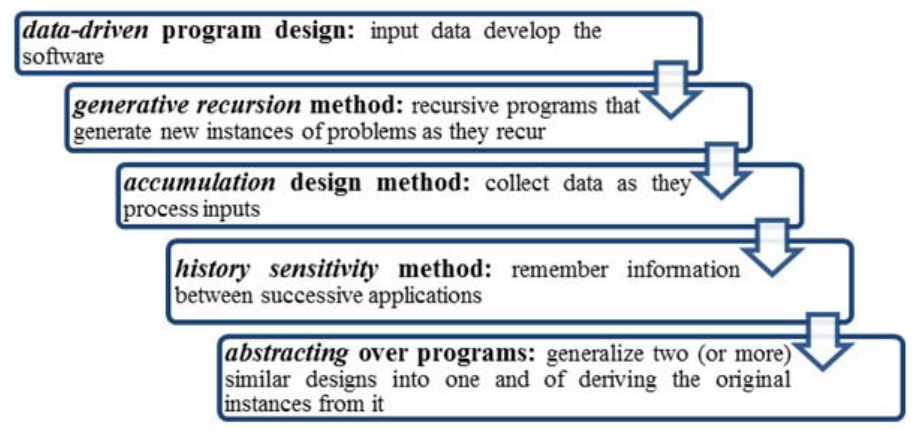

Fig. 2. Software design methods.

Developing CADOProSys Software the authors combine methods, based on program's level. Thus, at the beginning is used the data-driven method and, during the stages are used accumulation or history method.

\section{CADOProSys Software general structure}

CADOProSys Software was developed as educational software based on the need of both teachers and undergraduate to obtain production systems designed as accurate as possible. As any educational software, CADOProSys was specifically designed to lead a learner to develop an activity, not only to execute one. It was designed to satisfy both pedagogical and teaching setting.

There are two perspective based on which the software was developed: teachers and students. Teachers' requirements for this software were:

- support to supervise students $\left(T_{R} 1\right)$;

- challenging students $\left(\mathrm{T}_{\mathrm{R}} 2\right)$;

- designed for formal and informal learning $\left(\mathrm{T}_{\mathrm{R}} 3\right)$;

- determine students to argument and make decision $\left(\mathrm{T}_{\mathrm{R}} 4\right)$;

- teaching principles not formula $\left(\mathrm{T}_{\mathrm{R}} 5\right)$;

- develop the ability to design a complex production system $\left(\mathrm{T}_{\mathrm{R}} 6\right)$;

- explain the correlation between parameters $\left(T_{R} 7\right)$. 
From students' point of view, the software should be:

- user friendly (SR1);

- have tutorials (SR2);

- comprehensible (SR3);

- steps imposed by software in designing production systems to be correlated to curriculum (SR4);

- correlation to real manufacturing systems (SR5).

Thus, the QFD chart [10] (quality function development) is shown in Table 2.

Table 2. QFD chart for CADOProSys Software.

\begin{tabular}{|c|c|c|c|c|c|c|c|c|}
\hline & \multicolumn{7}{|c|}{ Teachers' requirements } & \multirow[b]{2}{*}{$\begin{array}{l}\text { Benchmark* } \\
\text { (Tecnomatix) }\end{array}$} \\
\hline & $\mathrm{T}_{\mathrm{R}} 1$ & $\mathrm{~T}_{\mathrm{R}} 2$ & $\mathrm{~T}_{\mathrm{R}} 3$ & $\mathrm{~T}_{\mathrm{R}} 4$ & $\mathrm{~T}_{\mathrm{R}} 5$ & $\mathrm{~T}_{\mathrm{R}} 6$ & $\mathrm{~T}_{\mathrm{R}} 7$ & \\
\hline \multirow{5}{*}{ 总 } & $\mathrm{X}$ & & $\mathrm{X}$ & & & & $X$ & $\mathrm{~S}$ \\
\hline & & & & & & & $\mathrm{X}$ & M \\
\hline & $\mathrm{X}$ & $\mathrm{X}$ & $\mathrm{X}$ & $\mathrm{X}$ & $X$ & $\mathrm{X}$ & $\mathrm{X}$ & $\mathrm{M}$ \\
\hline & $\mathrm{X}$ & $\mathrm{X}$ & $\mathrm{X}$ & & $X$ & $\mathrm{X}$ & & $\mathrm{S}$ \\
\hline & & $\mathrm{X}$ & & $\mathrm{X}$ & & $\mathrm{X}$ & & $\mathrm{M}$ \\
\hline & & $\begin{array}{c}3 \text { levels } \\
\text { of } \\
\text { difficulty }\end{array}$ & $\begin{array}{l}>3 \text { self- } \& \\
\text { final } \\
\text { assessments }\end{array}$ & $\begin{array}{c}3 \\
\text { different } \\
\text { options } \\
\end{array}$ & & $\begin{array}{l}3 \text { levels of } \\
\text { complexity }\end{array}$ & $\begin{array}{l}\text { hint for } \\
\text { each } \\
\text { formula }\end{array}$ & \\
\hline & \multicolumn{7}{|c|}{ Teachers' targets } & \\
\hline
\end{tabular}

* $\mathrm{S}=$ strong competitive position; $\mathrm{M}=$ medium competitive position; $\mathrm{W}$ = weak competitive position

CADOProSys Software was developed based on the production systems' design principles and correlated with QFD chart identified and presented in $\S 2.1$. of the present paper. It was designed to be able to determine: typology of manufacturing system; technical and economical parameters of manufacturing system; human resource design; layout; logistics (supply-chain and material handling); costs (Figure 3). Software allows the students to both design new production systems and develop an existing system through implementing new product, or increasing the production.

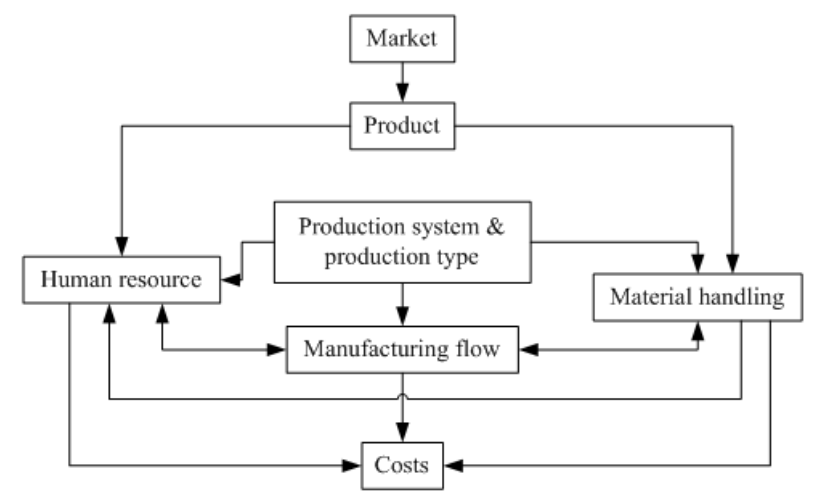

Fig. 3. Modules of CADOProSys Software.

Each module is a combination of requirements and results that interconnect to other module or direct with the conclusion page. Because CADOProSys Software is an educational one, after each selection done by students are synthetized the generated restrictions. As example, in figure 4 is presented the window that allow selection of production system type and explained what will determine in other modules (some options 
will be inactive). Thus, will be automatically activated the modules oriented on production type (Figure 5), in material handling module will be disabled the option "no material handling requirement". In this way, students will not be able to uncorrelate the production system type and production type or material handling equipment, increasing the quality of design and decreasing the design time.

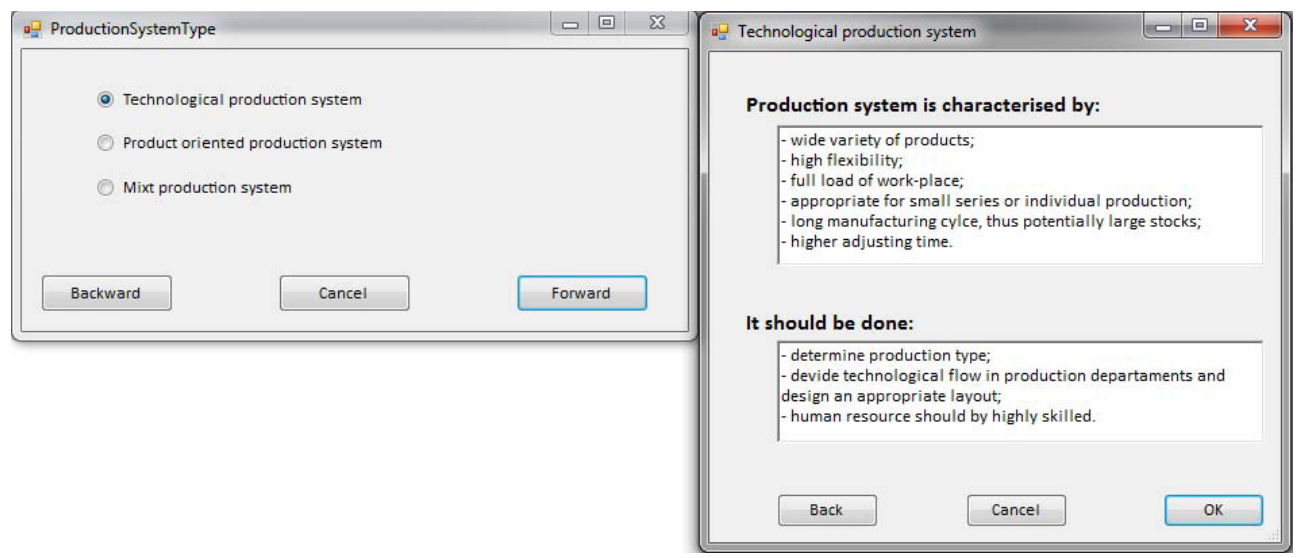

Fig. 4. Production systems type selection.

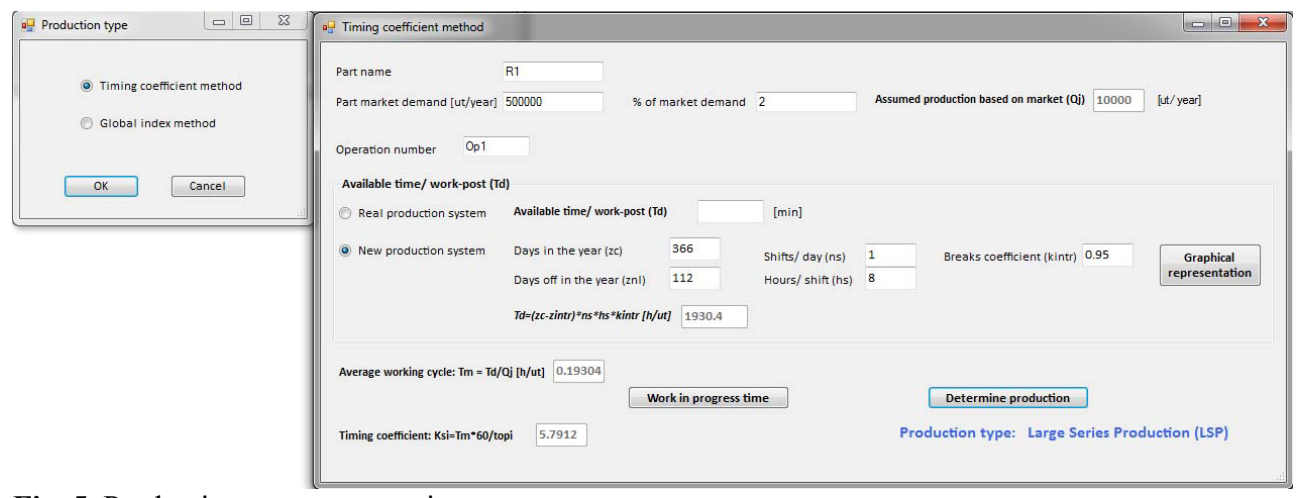

Fig. 5. Production type computation.

Modules of the CADOProSys are complex and allow the user to obtain data as final results shown on the active window and/ or Excel files that may be used for other purposes. Such an example is the production type computation module that generates an Excel file that contains data for each operation for each product (Figure 6, based on data shown in Figure 5). This module has also a submodule that allows either computation of work-in progress time or input this time based on firm's normative.

\begin{tabular}{|c|c|c|c|c|c|c|c|c|c|c|c|}
\hline \hline A & A & B & C & D & E & F & G & H & I & J & K \\
\hline 1 & Part name & $\begin{array}{c}\text { Part market } \\
\text { demand } \\
\text { \% market } \\
\text { demand }\end{array}$ & Qj & & & & & & & \\
\hline 2 & R1 & 500000 & 2 & 10000 & & & & & & & \\
\hline 3 & & & & & & & & & & & \\
\hline & $\begin{array}{c}\text { Operation } \\
\text { number }\end{array}$ & zC & znl & ns & hs & kintr & Td & Tm & Topi & Ksi & Production type \\
\hline 5 & Op1 & 366 & 112 & 1 & 8 & 0.95 & 1930.4 & 0.19304 & 2 & 5.7912 & Large Series Production (LSP) \\
\hline 6 & Op2 & 366 & 112 & 1 & 8 & 0.95 & 1930.4 & 0.19304 & 1 & 11.5824 & Medium Series Production (MSP) \\
\hline 7 & & & & & & & & & & & \\
\hline
\end{tabular}

Fig. 6. Production type computation: Excel file. 


\section{Conclusions}

CADOProSys Software is in continuous development and testing, adapting to students curriculum. The development of the software was started only last year, but some of its module was already tested with the undergraduates and graduates. The tests were oriented on three directions: ability to transmit knowledge (Figure 7); capability of the students to assimilate these knowledge and time consumption. The most relevant results were obtained after tested the graduates (they already have knowledge and are more critical to the software because they are able to see better the details). The tests were done due to the main objective of the software: to be educational and adapted to the curriculum and students' requirements.

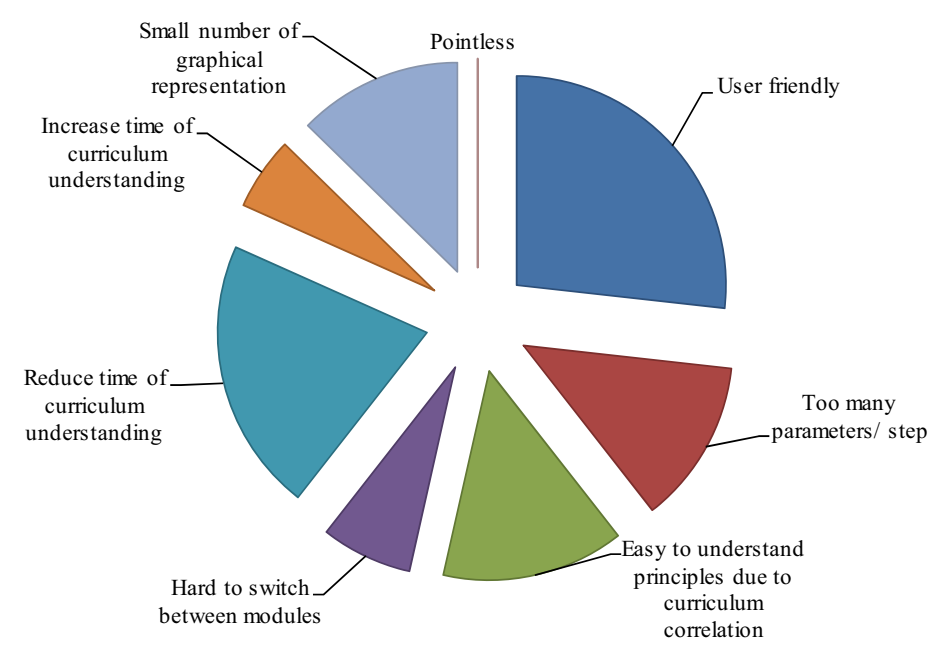

Fig. 7. Graduates and undergraduates opinions relative to CADOProSys ability to transmit knowledge.

As it can be seen from the answers given by graduates and undergraduates, CADOProSys should be improved in the following directions: reduce number of parameters/ step (by creating more windows/step); introduce more graphical representation. In conclusion, from respondents' point of view the software was useful in learning process and reduces time of computation.

\section{References}

1. W. Stevenson, Operations Management (McGraw-Hill PH., New York, 2012)

2. Software Advice. http://www.softwareadvice.com/manufacturing

3. Digital Manufacturing Solutions. DELMIA. http://4dmsco.com/

4. Siemens Tecnomatix https://www.plm.automation.siemens.com/en_us/products/tecnomatix/

5. E. Klimczak, Design for Software: A Playbook for Developers (Wiley P.H., Chichester, 2013)

6. N. Slack, A. B. Jones, R. Johnston, Operations management (Pearson P.H., London, 2013)

7. D. Unger, S. Eppinger, CJEN 22, 689 (2011)

8. D. Cochran, A. Chu, M.U. Jafri, Z. Bi, JIII 2, 65 (2016)

9. A. Thecle,Y. Benama, N. Perry, Adv. PMS 440, (2014)

10. P. Tchounikine, Computer science and educational software design (Springer, Berlin, 2011) 